\title{
La documentación literaria aplicada al Registro Arqueológico: Las técnicas de construcción de los graneros romanos rurales*
}

\section{The literary documentation applied to the Archaeological Registry: The techniques for construction of the rural roman granaries}

\author{
P. JaVIer Salido Domínguez ${ }^{1}$
}

\begin{abstract}
RESUMEN
ABSTRACT

La información aportada por los escritores clásicos resulta fundamental para el estudio de la arquitectura romana, especialmente para el conocimiento de las edificaciones que, como los graneros, han llegado hasta nosotros en un lamentable estado de conservación. Los textos latinos constituyen en la actualidad un testimonio excepcional para examinar las técnicas empleadas en la construcción y determinar las características que definen un granero, así como diferenciar

The information of Latin texts is important for the study of the Roman architecture, specially for the analysis of buildings, like the granaries. The Latin texts are an exceptional testimony to examine the techniques of construction of the barns and the architectonic characteristics of the different types of Roman structures designed to store the grain. We presented here an analysis of the information contributed by the Latin writers and the archaeological data.
\end{abstract} correctamente los tipos de graneros de

* Este trabajo se ha desarrollado en el marco del proyecto de investigación Formas de ocupación rural en el cuadrante Noroccidental de la Península. Transición y desarrollo entre las épocas romana y medieval (Territoria) (HUM 2004-04010-C02-02/HIST), cuya Investigadora Principal es la prof. Carmen Fernández Ochoa.

1. Departamento Prehistoria y Arqueología de la UAM. 
época romana. Para ello, se presenta un estudio centrado en el análisis de la información aportada por las fuentes escritas y los datos que nos ofrecen las excavaciones arqueológicas.

\section{PALABRAS CLAVE}

Península Ibérica, establecimientos rurales, graneros, horrea, silos.
KEY WORDS

Iberian peninsule, rural settlement, granaries, horrea, silos.

\section{LA DEFINICIÓN DE LOS TÉRMINOS LATINOS REFERIDOS A LOS GRANEROS: PUTEI, SIRI, GRANARIA, HORREA ${ }^{2}$}

Los agrónomos romanos dedican una parte de su trabajo a determinar los criterios que deben seguir quienes deciden construir un granero en un centro de explotación agraria. El término genérico empleado para referirse a este tipo de construcciones es la palabra latina granarium ${ }^{3}$ y este concepto engloba los diferentes sistemas de almacenamiento de grano. Los agrónomos romanos mencionan tanto la construcción de silos excavados en la tierra como la edificación de graneros sobreelevados. Varrón nos informa que se excavaban silos (putel) en los campos de Cartagena y Huesca en Hispania Citerior y siri (grutas excavadas) en la Capadocia y Tracia para almacenar en su interior el grano ${ }^{4}$. Advierte de la necesidad de una preparación previa de las paredes y del suelo para su conservación y de colocación de paja en el interior ${ }^{5}$, así como de la instalación de un cierre que impida la entrada de aire en su interior. Columela también menciona la existencia de estos de-

2 Las abreviaturas de los autores y obras clásicas se exponen de acuerdo con el index de la obra Thesaurus Linguae Latinae (Teubneri, Stuttgart, Leipzig). Las traducciones expuestas se han realizado a partir de las siguientes obras inglesas: Columela, Res Rustica (Ash, H. B., 1977); Plinio, Historia Natural (Rackham, H., 1971); Varrón, De agri cultura (Hopper, W. D. y Ash, H. B., 1979); Varrón, De Lingua Latina (Kent, R. G., 1977); Vitruvio, De architectura (Granger, F., 1985). La traducción de los fragmentos de Opus agriculturae de Paladio han sido retomados directamente de la publicación de Moure Casas, A. 1990.

${ }_{3}$ Marco Terencio Varrón, escritor de época republicana, en su obra De Lingua Latina, se refiere al granero con el término granarium, pero no menciona, sin embargo, otra palabra también empleada, horreum: «De aquí [sc. de panis «pan»], panarium ["cesto del pan»] donde lo conservaban, equiparable a granarium, donde guardaban el grano del trigo; de aquí viene ese término» (Varro. ling. 5, 105).

4 «Otros tienen graneros subterráneos, grutas que llaman sirus como en Capadocia y Tracia. Otros emplean puteos como en la España Citerior y en los campos de Cartagena y Huesca. El suelo de estos pozos se cubre de paja; no penetra en ellos la humedad, porque no se abren nunca, no se deja penetrar el aire, si no es que hay que echar mano de esta reserva por lo cual no hay peligro de que se meta allí el gorgojo. El trigo se conserva en estos pozos por unos 50 años y el mijo podría conservarse más de 100» (Varro. rust. 1, 57, 2).

5 Las paredes de los silos podrían contar con un revestimiento de arcilla con el fin de aislar el grano de la humedad. Sin embargo, la experimentación ha demostrado que disminuye su capacidad de germinación, porque el revestimiento tiene que estar húmedo para evitar la introducción de aire en el silo (Reynolds, P. J., 1988). En cambio, el uso de paja, como señala Varrón, parece más apto porque absorbe más fácilmente la humedad (Alcalde, G. y Buxó, R., 1992). 
pósitos estancos de grano, que denomina también siri 6 . La apertura continuada de éstos tendría como consecuencia la corrupción y fermentación del producto almacenado, y éste es un dato que hay que tener en cuenta a la hora de analizar la capacidad de producción de una comunidad concreta.

Además de estos graneros excavados en la tierra, las fuentes escritas nos informan de la realización de almacenes construidos. Varrón establece una diferencia entre dos tipos (Varro. rust. 1, 57, 2-3): granaria sublimia o graneros elevados ${ }^{7}$ y un tipo de granero elevado y suspendido (supra terram granaria in agro), que Varrón ubica en Hispania citerior y Apulia $^{8}$. El grano almacenado en su interior es ventilado no sólo por los lados, con el aire que penetra por las ventanas, sino también por el que pasa por la parte inferior del pavimento. El registro arqueológico ha permitido documentar este tipo de construcción en época ibérica en el Levante peninsular ${ }^{9}$. No obstante, es importante indicar que estos graneros se encuentran en el ámbito urbano ibérico, y la misma tipología corresponde en cambio a los graneros sobreelevados romanos rurales.

A estos tipos de graneros ya señalados, Columela, el más insigne agrónomo de la Antigüedad, añade uno diferente. Se trata de un horreum abovedado, cuyo suelo está construido con opus signinum ${ }^{10}$, que permite no sólo aislarlo de la humedad, sino también evitar la entrada de animales a través de las esquinas de la pared. Este dato resulta interesante, si se tiene en cuenta que en la península lbérica han sido excavadas estructuras interpretadas como horrea pavimentados con opus signinum. Tal es el caso del horreum de Tinto Juan de la Cruz (Pinto, Madrid $)^{11}$.

Una vez señaladas las diferentes clases de graneros existentes, es importante tratar de determinar el significado de los términos empleados relativos a los graneros sobreelevados. Desde la época republicana, los agrónomos romanos emplean indistintamente el término horreum y granarium para referirse a este tipo de estructuras. El propio Varrón indica que «es indudable que, cuando se trata de vi-

6 «Si no existiera humedad en absoluto, podrías guardar el cereal incluso bajo tierra, como hacen en ciertas provincias ultramarinas, donde —en una especie de pozos que llaman siri- la tierra exhausta acoge los frutos producidos por ella» (Colum. 1, 6, 16).

7 «En cuanto al trigo, hay que encerrarlo en granero elevado que reciba la acción de los vientos del Norte y del Este y en donde la humedad no pueda penetrar por ningún lado» (Varro. rust. 1, 57, 1).

8 «Otros, por último, construyen en su propio campo unos graneros suspendidos como en la Hispania citerior y en Apulia. Estos graneros son ventilados no sólo por los lados, con el aire que penetra por las ventanas, sino también por el que sopla por debajo del piso» (Varro. rust. 1, 57, 3).

9 García, D., 1997; Gracia, F., 1995; Gracia, F. y Munilla, G., 1999.

10 «A algunos les parece el mejor depósito para el cereal un horreum abovedado, cuyo suelo terrizo, antes de pavimentarlo, se cava y empapa con alpechín nuevo sin sal, para apelmazarlo luego con mazos el opus signinum; a continuación, una vez seco, se extiende por encima con procedimiento similar una capa de ladrillo que se asienta con cal y arena mezcladas con alpechín en lugar de agua, se apisona luego muy fuertemente y se iguala. $Y$ todas las junturas de paredes y suelo se rellenan y cubren con masa de ladrillo, pues de ordinario cuando una construcción presenta grietas en esos sitios, proporciona cavidades y escondrijos a los animales que viven bajo tierra» (Colum. 1, 6, 12-13).

11 Morín de Pablos, J., et alii, 2001, 2002; Barroso Cabrera, R. y Morín de Pablos, J., 2002. 
ñas, hay que disponer de bodegas más amplias y, si la finca se destina al cultivo del trigo, han de prepararse más grandes los horrea» (Varro. rust. 1, 11, 2) ${ }^{12}$. No obstante, un estudio minucioso de las fuentes escritas permite establecer una cierta diferenciación, más teórica que real, entre ambas construcciones. El granarium constituye el término genérico para referirse al granero; en cambio, el horreum contendría además de grano, otro tipo de productos, como áridos, frutos, forraje y verduras $^{13}$.

Plinio (s. I d.C.) diferencia ambos edificios en función del material empleado en su construcción. Según este escritor, el horreum estaría construido con paredes de ladrillo que no permiten la entrada de corrientes de aire en el interior ${ }^{14}$, y los granaria serían edificios de madera sustentados por columnas, cuyo contenido es ventilado por los lados y por debajo ${ }^{15}$. La información aportada por Columela, en cambio, permite distinguir una diferenciación terminológica. El hecho de que, para explicar las características de un horreum, el agrónomo latino tome como referencia el tipo de construcción de un granarium es significativo, puesto que indica que ambas construcciones son similares en cuanto a su construcción, pero diferentes en su finalidad ${ }^{16}$. No obstante, la técnica constructiva es tan similar que un horreum cumpliría las mismas funciones que un granarium, siempre y cuando éste reuniese las condiciones óptimas para la conservación del grano ${ }^{17}$. En definitiva, es muy posible que genéricamente se emplease el término granarium para referirse al granero, tanto al subterráneo como al sobreelevado, pero en los tratados de agronomía se tiende a confundir este término con el concepto horreum, edificio donde también se almacenaba grano. Así pues, solamente un tratamiento y análisis adecuado de los restos arqueobotánicos permite determinar el tipo de producto que se almacenaba, y por tanto, establecer una diferenciación práctica entre el horreum y el granarium.

A la luz de la información aportada por los agrónomos latinos, tanto horreum como granarium son términos válidos para referirse a los graneros sobreelevados de época romana. No obstante, difícilmente se puede interpretar como horreum un

12 Otro escritor de época tardorrepublicana, Marco Vitruvio Pollión emplea los mismos términos que Varrón para hacer mención a los graneros y también se refiere a la edificación de horrea: «Los horrea, los heniles, los almacenes de harina y los molinos parece que han de hacerse fuera de la villa para que las villas estén más protegidas del peligro del fuego» (Vitr. 6, 6, 5).

13 Daremberg, Ch. y Saglio, Edm., 1969.

14 «Algunos recomiendan horrea construidos con paredes de ladrillo de tres pies de ancho [tripedales] y llenarlos por la parte superior, no permitiendo la entrada de corrientes de aire ni tener ventana alguna» (Plin. nat. 18, 73).

15 «En otros lugares, por el contrario, construyen sus graneros de madera, suspendidos sobre columnas, prefiriendo dejar que el aire sople por todos lados y aún por debajo» (Plin. nat. 18, 73).

${ }_{16}$ La similitud entre ambas construcciones queda patente en el comentario de Columela: «Sin embargo, como a veces mucha cantidad de aceituna supera la capacidad de trabajo de los molineros, conviene que haya un horreum, construido sobre pilares, adonde puedan llevarse los frutos; y este sobrado debe ser parecido a un granero y tener compartimientos tan numerosos como exija la cantidad de aceituna, para separar y poner aparte la cosecha de cada día» (Colum. 12, 52, 3).

17 «Un horreum que sea seco y libre de humedad, se considera adecuado para el trigo» (Colum. 12, $2,2)$. 
granero excavado en la tierra. Por otro lado, es cierto que algunos escritores latinos utilizan esta palabra para referirse al almacén donde se guardaban los útiles agrícolas, sin embargo, no parece que éstas fuesen las funciones principales del horreum $^{18}$. Por ello, considero que no deben interpretarse como horrea estancias destinadas al almacenamiento de herramientas, utensilios $u$ otro tipo de enseres ${ }^{19}$. También algunos fragmentos aluden al uso de la palabra horreum para referirse a la bodega de vino ${ }^{20}$, sin embargo, según se desprende de la lectura de los tratados de agronomía, es más correcto restringir el significado de este término para referirse exclusivamente al almacén de productos agrícolas —entre ellos, el grano-o para denominar el granero ${ }^{21}$; en cambio, los términos cella vinaria o cella olearia definen de un modo preciso los espacios reservados al almacenaje de dolia utilizados como contenedores de vino o aceite respectivamente. La imprecisión en el uso de este término ha permitido en ocasiones interpretar erróneamente las cellae vinariae como horrea ${ }^{22}$.

\section{LA INFORMACIÓN ESCRITA REFERIDA A LOS GRANEROS Y EL REGISTRO ARQUEOLÓGICO}

Los escritores latinos nos aportan información interesante sobre la ubicación, orientación, organización interna y las técnicas constructivas de los graneros, da-

18 Columela aconseja la construcción de un horreum, donde eventualmente se pueden guardar las herramientas y útiles agrícolas (Colum. 1,6,7), pero seguidamente el escritor romano nos informa que la principal función del edificio es servir como almacén de productos, frutos y grano (Colum. 1, 6, 9-10: «Respecto a la parte de almacenamiento, se divide en bodega de aceite, prensa, la bodega de mosto cocido, heniles, pajares, despensas y horrea, con vistas a que, de entre éstas, las dependencias que están directamente sobre el suelo se dediquen a guardar los líquidos — por ejemplo, vino o aceite destinados a la venta—, mientras los áridos — granos, heno, hojas, paja y demás forraje- han de amontonarse en tablados»). En cuanto al uso del término horreum para referirse a la bodega de vino, es importante destacar que siempre es definida como cella vinaria por los agrónomos latinos y diferencian con bastante claridad ambos conceptos. Varrón distingue dos espacios dedicados al almacenamiento de productos: el vino y el aceite en el interior de las cellae y áridos como habas o el heno en un lugar sobreelevado, encima de un sobrado de madera: «Los productos como el vino y el aceite, en un lugar llano en las cellae, (...), áridos como habas o el heno en los tabulata» (Varro. rust. 1, 13, 1). Columela también diferencia las dependencias que están directamente sobre el suelo para guardar los líquidos, como el vino o aceite, de los espacios situados en alto sobre los tabulata donde se amontonaban los áridos, como grano, heno, hojas, paja y forraje (Colum. 1, 6, 9-10).

${ }_{19}$ En el interior del horreum de la villa romana de El Saucedo (Talavera la Nueva, Toledo), se hallaron numerosos útiles que tenían una función agropecuaria (Castelo Ruano, R., Bendala Galán, M. y Arribas Domínguez, R., 1998; Castelo Ruano, R., et alii, 1999), sin embargo, no hay duda de que la función principal de este edificio es la de servir de almacén de grano, como evidencian los apoyos sobre los que se situaba el sobrado de madera (Castelo Ruano, R., et alii, 2006).

20 Senec. epist. 114, 25; Hor. carm. 3, 28, 7.

21 El término horreum, entendido como granero, es el más empleado por los agrónomos latinos: Varro. rust. 1, 11, 2; Plin. nat, 18, 73; Colum. 1, 6, 9-17; 12, 52, 3; 12, 2, 2; Pallad. 1, 19, 1-3.

22 Algunos espacios destinados al almacenaje de dolia, ya se trate de cellae vinariae u oleariae, han sido interpretados como horrea, como la estancia 7 de la villa romana de Torre Llauder (Clariana, J., y Prevosti, M., 1994), o el ámbito termal de la villa romana de Barrugat (Bítem, Tarragona), que sufre numerosas reformas en época tardorromana, y donde se instalan diversos dolia. Aunque no se han realizado análisis para determinar el tipo de producto contenido en el interior de estos recipientes cerámicos, parece más conveniente no definir este edificio como un horreum (Chavarría Arnau, A., 2004). 
tos que nos permiten, en último término, determinar la funcionalidad de una estancia o edificio como granero.

En relación a la ubicación de los graneros, Vitruvio indica que son edificios que se construyen generalmente aislados del resto de edificaciones, para evitar la propagación del fuego, de ahí que se tienda a separar de hornos y zonas de cocina (Vitr. 6, 6, 5). Esta disgregación del granero con respecto a otros ámbitos de carácter residencial probablemente explica la ausencia en el registro arqueológico de almacenes y graneros en numerosas excavaciones realizadas en la península Ibérica, centradas en el descubrimiento y conocimiento del área residencial de las villae. Este plano diseminado de los ámbitos residenciales y rústicos que configuran la villa romana es bien conocido en numerosas villae de la península lbérica ${ }^{23}$. En otros establecimientos rurales romanos, los edificios destinados al almacenamiento de grano se hallan más próximos a la zona residencial de la villa, aunque mantienen también un cierto aislamiento ${ }^{24}$. También es importante destacar que algunos horrea se situaban en zonas de altura, como el horreum de Doña María (Badajoz), ubicado sobre un altozano de $350 \mathrm{~m}$. de altura ${ }^{25}$.

23 La ubicación de los graneros aislada con respecto a la zona residencial se documenta en numerosas villae de la península lbérica. Este es el caso del establecimiento rural de Baños de Gilico (Calasparra, Murcia), cuya planimetría presenta un conjunto de edificios diferenciados en dos sectores extendidos en 8 hectáreas, uno correspondiente al hábitat doméstico, y otro definido por los edificios de almacenamiento de excedente agrícola (horrea) (García Blánquez, L. A., y López Campuzano, M., 1995). La pars rustica de la villa romana de La Sevillana (Esparragosa de Lares, Badajoz) formaba un bloque de construcciones exento con respecto a la zona residencial (Aguilar Sáenz, A., 1991a; 1991b; Aguilar Sáenz, A. y Guichard, P., 1993). Un esquema similar repite el horreum de la villa de Doña María (Esparragosa de Lares, Badajoz), que se halló en un recinto de altura situado al margen de la zona residencial (Aguilar Sáenz, A., y Guichard, P., 1991; 1993); también la pars rustica de Liédena (Navarra) (Taracena Aguirre, B., 1949; 1950) y el horreum de Los Términos/ Los Villares (Monroy, Cáceres), alejado del resto de construcciones (Cerrillo Martín de Cáceres, E., 2006a; 2006b; et alii, 1988; 1991). El yacimiento de Tossal del Moro (Corbins, Segriá, Lérida) tiene una organización espacial y topográfica que permite diferenciar visiblemente las edificaciones con respecto a su funcionalidad: el área residencial, el barrio artesanal y el sector agrícola y la necrópolis (Marí i Sala, I., y Revilla, V., 2003).

${ }^{24} \mathrm{La}$ construcción de graneros aislados, aunque bastante cercanos a la pars urbana, se documenta en centros de explotación agraria como la villa romana de Veranes (Gijón, Asturias), donde se construyó un horreum al Occidente de la zona residencial (Fernández Ochoa, C., 2003; Fernández Ochoa, C., Gil Sendino, F. y Orejas Saco del Valle, A., 2004). Al Suroeste de la pars urbana de la villa romana de Tinto Juan de la Cruz (Pinto, Madrid), se documentó un almacén de grano (Morin de Pablos, J., et alii, 2001, 2002; Barroso Cabrera, R. y Morin de Pablos, J., 2002). El ¿granarium? y ¿horreum? de la villa romana de Arellano (Navarra) se construyeron aislados de la zona residencial (Mezquíriz Irujo, M. A., 2003); el edificio 2 altoimperial de la villa romana de Tolegassos (Viladamat, Gerona) se encontraba en un lugar muy cercano al denominado Sector 1, donde se documentó la zona de la cocina, el lugar donde se guardaba la leña y la zona residencial donde habitaba el servicio rústico (cellae familiares) (Casas J., 1989; et alii, 1995). El ¿horreum? de la villa de Doña Ana II (Dos Hermanas, Sevilla) formaba parte del edificio donde se almacenaban dolia y se producía pan (Vargas Jiménez, J. M. y Romo Salas, A., 1993; 1997). El granero altoimperial de la villa de Sao Cucufate (Vila de Frades, Vidigueira, Beja) se encuentra aislado con respecto las estructuras rústicas, mientras que el de cronología bajoimperial está plenamente asociado a éstas. Ambos graneros se hallan inconexos con respecto a la zona residencial, aunque bastante próximos (De Alarcao, J., 1998; Etienne, R., 1990). En cambio, en otros yacimientos, el horreum se encontraba más integrado en el edificio residencial. Este es el caso de los dos graneros altoimperiales de Torre de Palma (Monforte, Portalegre) (Maloney, S., y Hale, J., 1996) y el horreum de Freiria (São Domingos de Rana, Cascais, Lisboa), que ocupa la zona central de la villa, en las cercanías de la entrada principal (Cardoso, G. y Encarnação, J. D'., 1992-3; 1999).

25 Aguilar Sáenz, A., y Guichard, P., 1991; 1993. 
Orientación ideal para la conservación de grano, según los agrónomos latinos

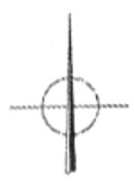

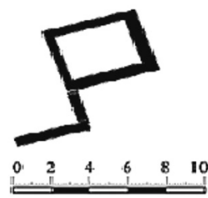

Arellano (Navarra)

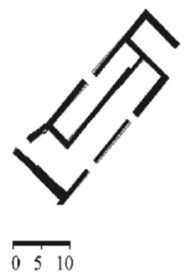

Liédena (Navarra)

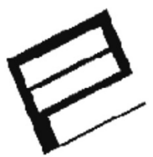

$02: 58$

Tinto Juan de la Cruz (Pinto)

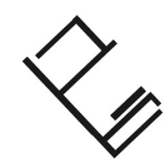

Carrión (Badajoz)

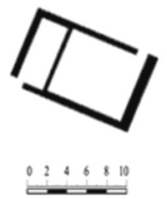

Doña Ana II (Sevilla)

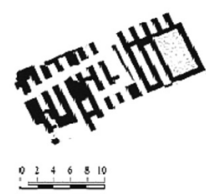

Freiria (Sâo Domingos de Rana)...

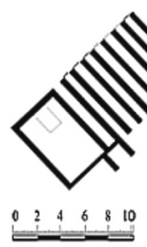

Los Términos

(Monroy, Cáceres)

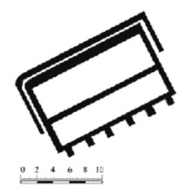

Veranes (Gijón)

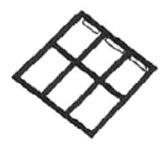

3

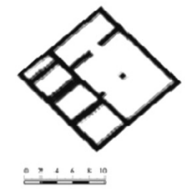

Sâo Cucufate (Vidigueira)

Orientación diferente a la propuesta por los agrónomos latinos
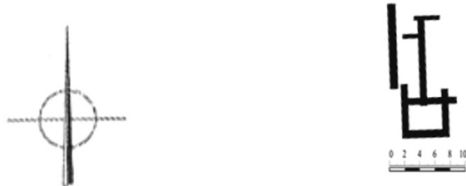

Doña Ana II (Sevilla)

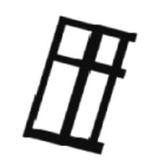

\begin{tabular}{rrrrrr}
$0 \quad$ & 4 & 6 & 8 & 10 \\
\hline
\end{tabular}

La Sevillana (Esparragosa de los Lares)

Fig.1. Orientación de los principales graneros romanos documentados en la Península Ibérica (sg. P. Javier Salido Domínguez). 
Los agrónomos romanos recomendaban además la construcción de graneros con una orientación determinada, de tal modo que las fachadas mayores se orientasen en dirección Norte-Sur para evitar que las altas temperaturas, provocadas por la mayor incidencia de los rayos solares en los lados Este y Oeste, secasen el grano almacenado ${ }^{26}$, incluso aconsejan construir ventanas orientadas hacia el Este y el Norte (Plin. nat. 18, 73). Así pues, los graneros con una planta rectangular se tendrían que construir, según estas recomendaciones, de manera que sean las fachadas menores las más expuestas al sol. El estudio de la plantas de los graneros documentados en la península lbérica permite concluir que generalmente se atienen a estos criterios, porque la fachada Este coincide con un lado menor. Sin embargo, presentan una ligera desviación, de modo que no recibe frontalmente los rayos solares, sino que éstos tienen una incidencia oblicua sobre el paramento Este del edificio (Fig. 1). Son numerosos los horrea que se construyeron siguiendo estas indicaciones, como el horreum y el granarium de la villa de Arellano (Navarra), el horreum de Freiria (São Domingos de Rana, Cascais, Lisboa), Liédena (Navarra), Los Términos (Monroy, Cáceres), Tinto Juan de la Cruz (Pinto, Madrid) y el altoimperial de la villa romana de Veranes (Gijón, Asturias). La misma disposición, aunque con diferente orientación, presentan los graneros de la villa romana de $\mathrm{Ca}$ rrión (Badajoz) y los graneros de cronología altoimperial y bajoimperial de Sao Cucufate (Vila de Frades, Vidigueira, Beja). En cambio, el horreum de la villa romana de La Sevillana (Esparragosa de Lares, Badajoz) y el documentado en la villa de Doña Ana II (Sevilla) presentan las fachadas mayores con una orientación completamente diferente a la propuesta por los agrónomos latinos. En definitiva, se tiende a construir, siguiendo sus indicaciones, porque resultan prácticas para la conservación del grano. No obstante, es cierto que existen otros factores que explican el cambio de ordenación. Así, por ejemplo la planta del horreum de la villa romana de Tinto Juan de la Cruz (Madrid) presenta una cierta inclinación con el fin de aprovechar el banco de tierra sobre el que se construye.

Es difícil encontrar en la documentación arqueológica datos referentes a las técnicas de construcción que, sin embargo, los textos de época romana nos aportan. Con ello, me refiero al tratamiento de las paredes con el fin de conseguir una solidez y resistencia del muro y una capa aislante frente a la humedad y los animales nocivos para el grano. Los agrónomos latinos insisten en cubrir y revestir las paredes del granero con diversos productos ${ }^{27}$. Los restos arqueológicos, más par-

26 «Los graneros que están orientados al recorrido del sol rápidamente deterioran el grano, y los alimentos que no se guardan con aquella orientación, no se conservan mucho tiempo» (Vitr. 1, 4, 2). Obviamente, se alude con la mención ad solis cursum al recorrido del sol, es decir, la orientación hacia el Este y Oeste. Por tanto, Vitruvio aconseja orientar la construcción del granero en sentido Norte-Sur con el fin de evitar que el grano se secase rápidamente

${ }_{27}$ Varrón aconseja que «las paredes y el piso deben revestirse de una capa formada por mármol machacado o al menos de arcilla mezclada con paja de trigo y orujo de oliva. Esto mantiene alejado al grano de las ratas y gusanos y contribuye al mismo tiempo a darle solidez y resistencia. Algunos untan el grano con las heces del aceite en la proporción de un quadrantal por cada mil modios, aproximadamente. Otros echan por encima o extienden por el granero greda de Calcidia o de Caria o ajenjo u otras sustancias análogas» (Varro. rust. 1, 57, 1-2). En cambio, Plinio defiende que «deben ser construidos sin cal 

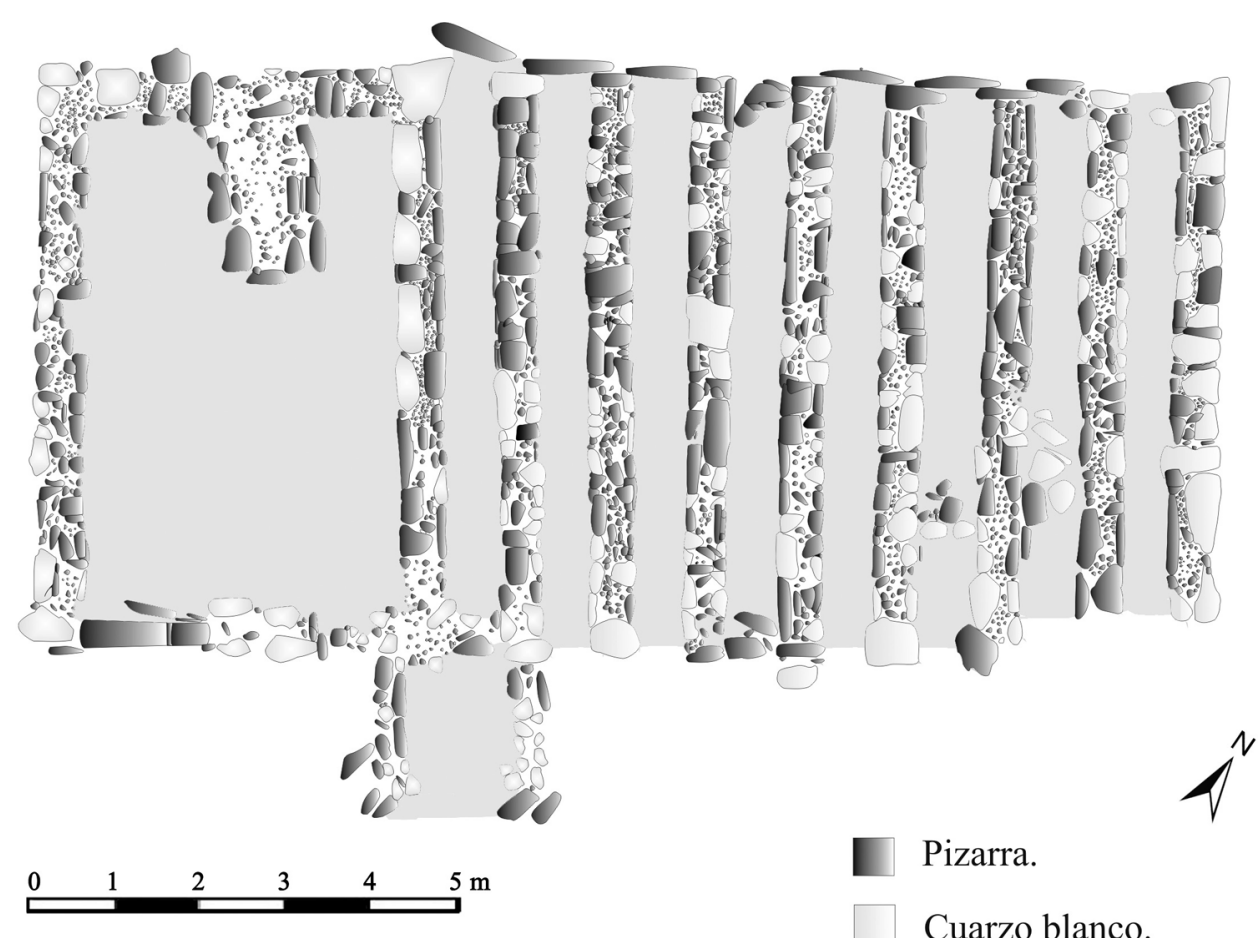

Pizarra.

Cuarzo blanco.

Fig.2. Planta del horreum de la villa romana de Los Términos (Monroy, Cáceres) (sg. P. Javier Salido Domínguez).

cos en este tipo de información, pueden ofrecer datos relativos al enlucido y encalado. El hallazgo de restos que nos indican que las paredes estarían revocadas o pintadas nos puede informar sobre la voluntad de conseguir un revestimiento y aislamiento de la cara interna del paramento.

Por el contrario, la Arqueología ha permitido constatar técnicas constructivas sobre las que las fuentes escritas apenas aportan información. Las excavaciones arqueológicas han puesto al descubierto la construcción de obras de drenaje que evitan la acumulación de agua cerca de los cimientos y aíslan de la humedad el grano contenido. En la villa romana de Veranes (Gijón, Asturias), se documentó la

porque ésta es nociva al trigo» (Plin. nat. 18, 73). Columela, al referirse a los horrea abovedados, nos informa de que «todas las junturas de paredes y suelo se rellenan y cubren con masa de ladrillo, pues de ordinario cuando una construcción presenta grietas en esos sitios, proporciona cavidades y escondrijos a los animales que viven bajo tierra (...). Las paredes se untan con alpechín y barro amasado; a éste, en lugar de paja, se le han añadido hojas secas de acebuche o, si no las hay, de olivo. Luego, cuando dicho revestimiento se ha secado, se salpica de nuevo con alpechín y, tras secarse éste, ya puede llevarse el grano. Todo ello parece que protege con gran eficacia la cosecha almacenada del daño que causan los gorgojos y bichos semejantes; caso de no ser entrojada convenientemente, sería devorada por ellos con toda rapidez» (Colum. 1, 6, 13-15). 
construcción de un canal de drenaje en el muro Norte del horreum ${ }^{28}$. En el granero de la villa de Los Términos (Monroy, Cáceres), se colocaron varias lajas de piedra en el extremo Norte con el fin de cerrar los vanos situados en la parte inferior del entarimado de madera y, de este modo, conseguir que el aire pasara al interior del edificio por el lado Sureste, ventilara el grano almacenado, y además se aislara de la humedad este extremo del edificio (Fig. 2). Tampoco nos informan los agrónomos latinos sobre la construcción de contrafuertes adheridos a las paredes de los graneros. Estos elementos constructivos contrarrestan la presión que ejercía el peso del cereal hacia los laterales y permitían la sustentación firme de la techumbre ${ }^{29}$. En la Península Ibérica, tanto el horreum de la villa romana de Veranes (Gijón, Asturias) como el excavado en Freiria (São Domingos de Rana, Cascais, Lisboa) presentan sólidos contrafuertes en sus fachadas.

La documentación arqueológica, debido al derrumbe y arrasamiento de los muros, no nos permite afirmar categóricamente si determinados graneros contaban o no con pequeñas aberturas que permitían el paso de la luz y el aire al interior. Los agrónomos latinos muestran cierta confusión al respecto ${ }^{30} \mathrm{y}$, aunque la mayoría insiste en que deberían tener aberturas pequeñas ${ }^{31}$, la humedad externa del enclave es un factor que determina su construcción.

Con respecto a la información referente al interior del edificio, los restos arqueológicos apenas nos permiten reconocer la compartimentación interna. Debió de ser común en la construcción de los graneros diferenciar el tipo de semilla o productos en el interior de dichas edificaciones, pero éste es un dato que permanece oculto en el registro arqueológico. La documentación escrita detalla el material de este tipo de compartimentos ${ }^{32}$. Solamente se ha localizado en el horreum de la villa romana de Arellano (Navarra) una estancia en semisótano, dividida en espacios (cellae), que posiblemente servirían para separar los alimentos de los forrajes $^{33}$.

${ }^{28}$ Fernández Ochoa, C., 2003; Fernández Ochoa, C., Gil Sendino, F. y Orejas Saco del Valle, A., 2004.

${ }^{29}$ Rickman, G., 1971.

30 «Algunos recomiendan horrea construidos con paredes de ladrillo (...), no permitiendo la entrada de corrientes de aire ni tener ventana alguna; otros dicen que deben tener sólo ventanas orientadas al Este o Norte» (Plin. nat. 18, 73).

31 «Estos graneros son ventilados no sólo por los lados, con el aire que penetra por las ventanas, sino también por el que sopla por debajo del piso" (Varro. rust. 1, 57, 3); «Los graneros han de ser accesibles mediante escaleras y recibir ventilación del viento norte a través de pequeñas aberturas» (Colum. 1, 6, 10).

32 Columela menciona en varias ocasiones la división del espacio interno de los graneros: «Se dividen los graneros en compartimientos para que cada fruto se coloque separadamente" (Colum. 1, 6, 13); «este sobrado debe ser parecido a un granero y tener compartimientos tan numerosos como exija la cantidad de aceituna, para separar y poner aparte la cosecha de cada día» (Colum. 12, 52, 3). Esta información es retomada directamente por Paladio en el siglo V d.C.: «si se espera mucha cantidad de semillas, destinaremos compartimientos separados para cada tipo de grano; si las tierras prometen menos por pobres, se dividirán los graneros con mamparas de cañizo, o reuniremos los menguados productos en cestos de mimbre» (Pallad. 1, 19, 2).

${ }^{33}$ Mezquíriz Irujo, M. A., 2003. 
En la actualidad, ante la ausencia de análisis paleobotánicos que nos permitan determinar si se almacenaban productos agrícolas en el interior de los edificios, la existencia de pavimentos sobreelevados constituye el testimonio más claro de la presencia de un granero. Los agrónomos latinos insisten en la importancia de construir a una cierta altura los pavimentos o sobrados de madera de los graneros para aislar de la humedad el contenido y evitar también la entrada de animales que pueden destruir la cosecha. Tanto Varrón como Columela diferencian el almacén donde se conserva el vino y el aceite (cellae) que se sitúa directamente sobre el terreno, y el edificio donde se almacenan áridos o el grano, cuyo pavimento se halla sobreelevado con respecto al suelo (Varro. rust. 1, 13, 1; Colum. 1, 6, 9-10). Los escritores romanos denominan a este suelo tabulatum, y por ello, se entiende el sobrado de madera sobre el que se acumulaba el grano. Tal es la importancia de este pavimento que, en ocasiones, se define el almacén como tabulatum ${ }^{34}$. El carácter perecedero de estos sobrados de madera impide reconocerlos en la documentación arqueológica, pero los restos constructivos nos informan de su presencia a partir de evidencias a las que, hasta la actualidad, no se les ha concedido importancia. Se han excavado edificios que pueden ser interpretados, sin duda, como graneros, porque se conservan los apoyos sobre los que se disponía directamente el entablado ${ }^{35}$. Entre éstos, los más determinantes son los muros paralelos situados a pocos metros entre sí, una trama muraria o pilares que sobreelevan el suelo ${ }^{36}$. Otros horrea presentan muros de gran anchura y cimentación profunda y estable, porque contaban con una segunda planta que cumplía la función de granero. En otros casos, la existencia de estos tabulata se testimonia por la aparición de varios huecos o mechinales, alineados a la misma altura, abiertos en las caras internas de los muros que permitían la introducción de vigas que servían de soporte de estos sobrados de madera. En cambio, se han documentado estructuras que podrían tener esta función, pero, ante la falta de datos concluyentes, es difícil determinar con seguridad su uso como granero. Por tanto, la ausencia de datos relativos a esta sustentación dificulta la determinación de la funcionalidad de numerosas estructuras. No quiere esto decir que todos los pavimentos sobreelevados correspondan al sobrado de un granero, pero pueden ofrecer datos concluyentes sobre su posible funcionalidad.

Por último, se puede destacar la ausencia en el registro arqueológico de graneros construidos en madera en Hispania. La existencia de estos graneros es una información que nos aportan los textos latinos ${ }^{37}$, y solamente un análisis eficaz del material encontrado permite su documentación. La presencia de agujeros de poste, clavos y material de construcción conservados en hierro constituyen pruebas

${ }^{34} \mathrm{Nec}$ enim, ut illa, foenisicia vidit arida in tabulato nec vindemiam in cella neque in granario messim (Varro. rust. 3, 2, 6). Podría traducirse como se expone a continuación: «Allí no se ven ni el heno secándose en el sobrado ni las uvas en la bodega ni la cosecha en el granero».

35 Rickman, G., 1971.

36 Salido Domínguez, P. J., e. p.

37 Plin. nat. $18,73$. 
determinantes de su existencia y una fuente de información importante para el estudio del poblamiento rural en época romana. Actualmente, no se puede aceptar la imagen de un paisaje rural sin la presencia de centros de explotación menores y una población campesina que vivía en cabañas y almacenaba su cosecha en graneros de madera. Los esfuerzos de los arqueólogos deben encaminarse a constatar este tipo de poblamiento que coexistía con las grandes villae romanas. En Europa, se conocen numerosos asentamientos romanos, cuya entidad constructiva se limita a la presencia de grandes edificios construidos en madera destinados al almacenamiento de grano (en ocasiones, con cimientos de piedra), pequeñas cabañas y zonas de actividad económica ${ }^{38}$. En el caso de Hispania, se ha podido registrar este tipo de poblamiento en la fase visigoda $^{39}$, pero se desconoce para la época imperial ${ }^{40}$. La ausencia de este tipo de graneros de madera en el registro arqueológico explica también el enorme vacío documental de amplias regiones, en las que se han encontrado evidencias de poblamiento romano, pero se desconocen las zonas productivas de los asentamientos.

\section{CONCLUSIONES}

Los tratadistas romanos mencionan varios términos relativos a las estructuras dedicadas al almacenamiento de grano, como putei, siri, granaria y horrea. La correcta definición de estos conceptos latinos permite aunar criterios y proponer una terminología común que impida llegar a conclusiones erróneas sobre este tipo de construcciones, derivadas de la inadecuada aplicación de la terminología antigua al resto constructivo romano. Con ello, me refiero a la denominación de horrea, empleada habitualmente en la bibliografía, para referirse a estructuras rústicas que, por sus características arquitectónicas y funcionales, deberían ser designadas como cellae vinariae o como cellae oleariae. También es importante destacar que los graneros debían contar con unos elementos constructivos que permitían mantener las condiciones de humedad ideales para la conservación del grano en su interior $y$, por tanto, no se puede generalizar e interpretar como graneros estructuras de las que se desconoce su técnica constructiva. Es habitual referirse a restos ar-

38 Los descubrimientos del norte de Europa evidencian en época altoimperial un poblamiento rural que apenas deja huella en el registro material y se documenta a partir de las improntas de los postes de madera. Se ha podido además precisar la funcionalidad de las estructuras que conforman el asentamiento (zonas de actividad, graneros, cabañas, etc.). Se podrían citar numerosos yacimientos, pero un buen ejemplo de ello son los hallazgos de Hauts de Clauwiers (Seclin, Nord) (Révillion, St., Bouche, K. y Wozny, L., 1994), La Gaubretière La Dugerie (Guillier, G., 2002). Esta técnica de construcción que emplea materiales perecederos, como la madera, está perfectamente constatada en el poblamiento rural bajoimperial (Van Ossel, P., 1992; 1995; 1997; Van Ossel, P. y Ouzoulias, P., 2000; 2001).

39 Vigil-Escalera Guirado, A., 2000; Rascón, S., 1991.

40 Recientemente, se han documentado restos constructivos en La Gravera de l'Eugeni (Artesa de Lleida) que podrían corresponder a una cabaña ocupada desde época republicana hasta la fase altoimperial (Sánchez, F., et alii, 2003b), aunque es lógico pensar que ésta no se hallaría aislada. En el interior de la Península Ibérica, se excavaron también estructuras que han sido interpretadas como hábitats de menor entidad (tuguria, cabannae) (Sánchez, F., et alii, 2003a). 
queológicos aparecidos en la pars fructuaria como almacenes, porque durante la excavación no se ha testimoniado material que permita determinar su funcionalidad. Sin embargo, como se ha tratado de exponer anteriormente, ni todos los almacenes pudieron cumplir la función de graneros ni los espacios reservados para guardar los útiles de labranza y enseres deben ser denominados horrea.

Aunque la información aportada por las fuentes escritas de época romana muestra una idealización del sistema de construcción, es muy útil para los arqueólogos tener en cuenta datos que pueden parecer previamente poco importantes, pero que resultan esenciales a la hora de excavar y recoger testimonios, así como de ofrecer una interpretación correcta de las estructuras arqueológicas encontradas. Entre éstos, se pueden destacar restos arqueológicos relacionados con el revestimiento de las paredes, la presencia de obras de drenaje que evita la acumulación de agua junto a los muros, la construcción de compartimentos en el interior del granero y, especialmente, la presencia de pavimentos sobreelevados, documentados por la aparición de apoyos/muros en el terreno o mechinales en las paredes. Otro testimonio de indudable importancia es el hallazgo de agujeros de poste y material arqueológico que permiten definir estructuras construidas en madera. En definitiva, se trata de definir los vestigios materiales que nos permiten determinar si los restos constructivos excavados pudieron cumplir la función de almacenes o depósitos de grano.

\section{BIBLIOGRAFÍA}

Aguilar SÁenz, A. (1991a): «Dependencias con funcionalidad agrícola en las villas romanas de la Península Ibérica», Gerión Anejos 3 (Alimenta. Estudios en Homenaje al Dr. Michel Ponsich), pp. 261279.

- (1991b): «Excavaciones arqueológicas en la villa romana de «La Sevillana». (Esparragosa de Lares, Badajoz). Campañas de 1987, 1988 y 1989", I Jornadas de Prehistoria y Arqueología en Extremadura (1986-1990). Extremadura Arqueológica 4. Mérida-Cáceres, pp. 445-456.

Aguilar SÁEnz, A., y GuichaRd, P. (1991): «Excavaciones arqueológicas en la «Dehesa de Doña María». (Esparragosa de Lares, Badajoz). Campañas de 1988 y 1989», I Jornadas de Prehistoria y Arqueología en Extremadura (1986-1990). Extremadura Arqueológica 4. Mérida-Cáceres, pp. 457-469.

- (1993): Villas romaines d'Estrémadure. Doña María, La Sevillana et leur environnement. Madrid.

AlCALDE, G. y Buxó, R. (1992): «Experimentació d'emmagatzematge i explotació de Triticum dicoccum Sch, a la Vall del Llierca (La Garrotxa)», Cypsela, 9, pp. 87-94.

ARIÑo GIL, E., y DíAZ, P. (1999): «La economía agraria de la Hispania Romana: colonización y territorio», Studia Historica. Historia Antigua, 17, pp. 153-192.

AsH, H. B. (1977): Lucius Junius Moderatus Columella. On agricultura. I: Res Rustica, I-IV. Harvard University press. William Heinemann LTD. Cambridge, Massachussets, Londres.

Badosa, E. (1999): Épodos y odas de Horacio. Ed. Comares. Granada.

Barroso Cabrera, R. y Morín de PABlos, J. (2002): “La época romana en la Comunidad de Madrid», en VV.AA.: Vida y Muerte en Arroyo Culebro: exposición del 4 de diciembre de 2001 al 31 de marzo de 2002, pp. 215-230.

BRogiolo, G. P. (dir.) (1996): La fine delle ville romane: trasformazioni nelle campagne tra tarda antichità e alto medioevo. $1^{\circ}$ convegno archeologico del Garda, Gardone Riviera (Brescia), 14 ottobre 1995. Documenti di archeologia 11. Mantova.

BuSANA, M. S. (2002): Architetture rurali nella Venetia romana. Le rovine circolari, 3. Roma.

CARDoso, G. y EnCARNAÇÃo, J. D'. (1992-3): «A villa romana de Freiria e o seu enquadramento rural», Studia Historica. Historia Antigua, 10-11, pp. 203-217. 
- (1999): «Economia agrícola da região de Olisipo: o exemplo de lagar de azeite da villa de Freiria», en GoRges, J.-G. y RodríGuez MARTiN, G.: Économie e Territoire en Lusitanie romaine Madrid: Casa Velázquez, 65, pp. 391-401.

CASAS J., (1989): L'Olivet d' en Pujol i Els Tolegassos. Dos Establiments agrícoles d'época romana a Viladamat (Campanyes de 1982 a 1988). Centre d'investigacions arqueologiques de Girona, serie monogràfica 10. Gerona.

CAsas, J., Castanyer, P., Nolla, J., y Tremoleda, J. (1995): El món rural d'época romana a Catalunya. L'exemple del Nord-Est. Centre d'Investigacions arqueològiques, serie monogràfica 15. Gerona.

Castelo Ruano, R., Bendala Galán, M., y Arribas Domínguez, R. (1998): «La villa romana de El Saucedo (Talavera de la Reina, Toledo)", Madrider Mitteilungen, 39, pp. 289-310.

Castelo Ruano, R., Jiménez Cañizos, O., Taléns, C., Aguado Molina, M., Arribas Domínguez, R., Sierra, C., Torrecilla Aznar, A. y López, A. (1999): «El yacimiento arqueológico de El Saucedo (Talavera la Nueva, Toledo): balance y perspectivas", CUPAUAM, 25.2, pp. 193-250.

Castelo, R., BAngo, C., López, A. y Aguado, M. (2006): «El Saucedo (Talavera la Nueva, Toledo). Un ejemplo de villa bajoimperial en la provincia de la Lusitania", en CHAVARRía ARNAU, A., ARCE, J. y PIETRO Brogiolo, G., (eds.): Villas Tardoantiguas en el Mediterráneo Occidental. Anejos AEspA 39, pp. 173-196.

Cerrillo Martín de Cáceres, E., (2006 a): «El asentamiento romano de la altiplanicie trujillano-cacereña en Extremadura (España). Paisajes agrarios y problemas de reconocimiento arqueológico", Agri Centuriati. An International Journal of Landscape Archaeology, pp. 73-90.

- (2006 b): «La villa romana de Monroy», en Chavarría Arnau, A., Arce, J. y Pietro Brogiolo, G. (eds.): Villas Tardoantiguas en el Mediterráneo Occidental. Anejos AEspA, 39, pp. 197-206.

Cerrillo Martín de Cáceres, E., Alvarado Gonzalo, M., Cerrillo Martín de Cáceres, F. J., Herrera García, G. y González LuCeÑo, M. ${ }^{a}$ A. (1988): «Excavaciones en la villa romana de Monroy (Cáceres). 1981-1985)", Extremadura Arqueológica, 1, pp. 167-186.

Cerrillo Martín de Cáceres, E., Herrera, G., Molano, J., De Alvarado, A., Castila, J., Hernández lóPEZ, M. (1991): «Excavaciones arqueológicas en la villa romana de «Los Términos», Monroy (Cáceres). Actuaciones y propuestas de futuro. (1984-1990)", I Jornadas de Prehistoria y Arqueología en Extremadura (1986-1990). Extremadura Arqueológica, 4, Mérida-Cáceres, pp. 379-386.

Chavarría Arnau, A. (2004): "Considerazioni sulla fine delle ville in Occidente», Archeologia Medievale, 31, pp. 7-19.

Clariana, J., y Prevosti, M. (1994): «Un exemple de ruralització a l'Antiguitat Tardana: la vil.la de Torre Llauder», III Reunió d’Arqueología Cristiana Hispánica, Maó, 12-17 de setembre de 1988. Monografies de la Secció Històrico-Arqueològica 2. Institut d'Estudis Catalans, Barcelona, pp. 117-126.

DAREMBERG, Ch. y SAGLIO, E. (1969): Dictionnaire des Antiquitès grecques et romaines d'après les textes et les monuments. Contenant l'explication des termes...et en général a la vie publique et privée des anciens. Ouvrage rédigé par une société d'écrivains spéciaux, d'archéologues et de professeurs. Graz: Akademische Druck.

De Alarcao, J. (1998): «La villa romana de San Cucufate», en Álvarez Martinez, J. M. y Almagro-GorBEA, M.: Hispania: el legado de Roma en el año de Trajano. Museo Nacional de Arte Romano, Mérida Febrero-Abril de 1999, pp. 441-444.

DUPRÉ, N. (1991): «Le stockage des céréales dans le bassin de l'Ebre à l'époque romaine», Gerión, Anejos 3 (Alimenta. Estudios en Homenaje al Dr. Michel Ponsich), pp. 205-217.

ETIENNE, R. (1990): Les villas romaines de Sao Cucufate. París.

FERNÁNDEZ OCHOA, C. (2003): El lenguaje de las piedras. La recuperación del patrimonio arqueológico de Gijón. Gijón.

Fernández OchoA, C., Gil Sendino, F., y Orejas Saco del Valle, A. (2004): «La villa romana de Veranes. El complejo rural tardorromano y propuesta de estudio del territorio", $A E s p A, 77$, n. ${ }^{\circ} 189-190$, pp. 197220.

FRANCOVICH, R. y HODGES, R. (2003): Villa to village: the transformation of the Roman countryside in Italy, c. 400-1000. Duckworth debates in archaeology. London.

García Blánquez, L. A., y López Campuzano, M. (1995): «Baños de Gilico: continuidad de una aglomeración rural romana (siglos I-IV d. C.) en la cuenca del río Quípar (Calasparra, Murcia)", en NoGUeRA Celdrán, J. M., (coord.): Poblamiento rural romano en el Sureste de Hispania. Universidad de Murcia, pp. 275-292.

GARCíA, D. (1997): «Les structures de conservation des céréales en Mediterranée Nord-occidentale au premier millénaire avant J.-C.: innovations techniques et rôle économique», en GARCIA, D. y MEEKS, D.: Techniques et économie antiques et médiévales: le temps de l'innovation: colloque international (C.N.R.S.), Aix-en-Provence, 21-23 mai 1996. Archéologie aujourd'hui, pp. 88-95. 
Gracia Alonso, F. (1995): «Producción y comercio de cereal en el N.E. de la Península Ibérica entre los siglos VI-II a.C.», Pyrenae, 26, pp. 91-113.

Gracia, F. y MunilLA, G. (1999): «Los graneros sobreelevados en el Mediterráneo Occidental», en Buxó, R. y Pons, E., (eds.): Els productes alimentaris d'origen vegetal a l'edat del ferro de l'Europa occidental: de la producció al consum. Actes del XXII col?loqui internacional per a l'estudi de l'edat del ferro, pp. 339-349.

Granger, F. (1985): Vitruvius. On architecture, II. Harvard University press. Cambridge, Massachussets.

GRASSIGLI, G. L. (1995): «La villa e il contesto produttivo nel paesaggio della Cisalpina», en QUILICI, L. y QuILICI GIGLI, S.: Agricoltura e commerci nell'Italia Antica. Atlante Tematico de Topografia Antica, pp. 221-240.

GUILLIER, G. (2002): «Un établissement rural augustéen et tibérien à La Gaubretière La Dugerie», Revue archéologique de l'Ouest, 19, pp. 117-128.

Hopper, W. D. y Ash, H. B. (1979): Marcus Porcio Cato. On agriculture. Marcus Terentius Varro. On agriculture. Harvard University press. William Heinemann LTD. Cambridge, Massachussets, Londres.

KeNT, R. G. (1977): Varro. On the Latin language, I: books V-VII. Harvard University press. William Heinemann LTD. Cambridge, Massachussets, Londres.

LÓPEZ PARDo, F. (1981): «Siri, granaria y horrea en Hispania Citerior», AEspA, 54, pp. 245-254.

LoRREn, C. y PÉRIN, P. (1995): L'habitat rural du haut Moyen Age (France, Pays-Bas, Danemark et Grande-Bretagne). Actes des XIVe Journées internationales d'Archéologie mérovigienne, Guiry-en-Vexin et Paris, 4-8 février 1993, Rouen.

Maloney, S., y Hale, J. (1996): «The villa of Torre de Palma (Alto Alentejo)», JRA 9, pp. 275-294.

Malrain, F., Matterne, V. y Méniel, P., (2002): Les paysans gaulois (IIle siècle- 52 av. J.C.). París.

MANNING, W. H., (1975): «Roman military timber granaries in Britain», Saalburg Jahrbuch. Bericht des Saalburg Museums, 32, pp. 105-129.

Marí I SAla, I., y Revilla, V., (2003): «El Tossal del Moro (Corbins, Segrià). Economia i organització de I'espai en una vil.la del territori d'llerda», en GenerA I MonelLs, M.: Actes de les Jornades d'Arqueologia i Paleontologia 2000: Lleida, 30 de novembre, 1 i 2 de desembre de 2000, vol. 1, pp. 343-361.

MATTERne, V. (2001): Agriculture et alimentation végétale durant l'âge du Fer et l'époque gallo-romaine en France septentrionale. Montagnac.

Matterne, V., YvineC, J.-H., GemeHL, D., avec la collaboration de Ch. RIQUIER, (1998): «Stockage de plantes alimentaires et infestation par les insectes ans un grenier incendié de la fin du lle siècle après J.C. à Amiens (Somme)», Revue Archéologique de Picardie, 3-4, pp. 93-122.

MezQuíriz Irujo, M. A. (2003): La villa romana de Arellano. Navarra.

Morín de Pablos, J., Jaque Ovejero, S., Oñate Baztán, P., Barroso Cabrera, R., Major González, M., Sanguino VÁzquez, J. y Penedo Cobo, E. (2002): «Los yacimientos de Tinto Juan de la Cruz -Pinto,

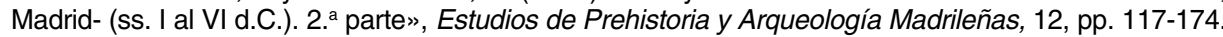

Morín de Pablos, J., Jaque Ovejero, S., Oñate Baztán, P., Major González, M., Barroso Cabrera, R., Sanguino VÁzquez, J. y Penedo Cobo, E. (2001): «Los yacimientos de Tinto Juan de la Cruz -Pinto, Madrid-(ss. I al VI d.C.)", Estudios de Prehistoria y Arqueología Madrileñas, 11, pp. 128-204.

MoRRIS, P. (1979): Agricultural Buildings in Roman Britain. BAR British series 70. Oxford.

Moure CAsAs, A. (1990): Paladio. Tratado de agricultura. Medicina veterinaria. Poema de los injertos. Biblioteca clásica de Gredos 135. Madrid.

PuRCELL, N. (1995): «The Roman villa and the landscape of production», en CORNELL, T. J. y LOMAS, K., Urban Society in Roman Italy, pp. 151-179.

Rackham, H. (1971): Pliny. Natural History, V: Libri XVII-XIX. Harvard University press. William Heinemann LTD. Cambridge, Massachussets, Londres.

RAScón, S. (1991): «La reocupación del mosaico del Aúriga victorioso (Villa romana de El Val). Un estudio de microespacio", Arqueología, Paleontología y Etnografía, 1, pp. 181-200.

RÉVILLION, St., BOUCHE, K. y WOZNY, L. (1994): «La partie agricole d'une grande exploitation rurale d'époque romaine: le gisement du Haut de Clauwiers, Seclin, Nord», Revue Nord Archéologie, 76, n. ${ }^{\circ}$ 308, pp. 99-146.

ReYnolds, P. J. (1988): Arqueología experimental: una perspectiva de futuro. Vic.

RICKMAN, G. (1971): Roman granaries and store buildings. Cambridge.

- (1980): The corn supply of Ancient Rome. Oxford.

Roca MeLIÁ, I. (1986): Séneca. Epístolas morales a Lucilio, II: Libros X-XX y XXII y epístolas 81-125. Biblioteca clásica de Gredos 72. Madrid.

Salido Domínguez, P. J. (e.p.): «Los sistemas de almacenamiento y conservación de grano en las villae hispanorromanas», Las villae tardorromanas en el Occidente del Imperio. Arquitectura y función. IV Coloquio Internacional de Arqueología de Gijón. 26, 27 y 28 de Octubre de 2006. 
Sánchez, F., Barroso Cabrera, R., Escolà Martínez, M., López, M., Morín de Pablos, J. (2003 a): «El hábitat rural durante la época romana en la Comunidad de Madrid», Bolskan: Revista de arqueología del Instituto de Estudios Altoaragoneses 20 (XXVII Congreso nacional de arqueología. III Mundo clásico), pp. 177-190.

Sánchez, F., Barroso Cabrera, R., Gallart i Fernández, J., Morín de Pablos, J., Escolà Martínez, M., López, M., YRAVEdRA, J. (2003 b): «La Gravera de l'Eugeni (Artesa de Lleida): una cabaña de época romana", Bolskan: Revista de arqueología del Instituto de Estudios Altoaragoneses 20 (XXVII Congreso nacional de arqueología. III Mundo clásico), pp. 163-176.

Taracena AguirRe, B. (1949): «Excavaciones en Navarra (VII, 1). La villa romana de Liédena», Príncipe de Viana, 10, pp. 353-382.

- (1950): «La villa romana en Liédena y el campo español en el Bajo Imperio», en VV.AA., Crónica del I Congreso Nacional de Arqueología y V del Sudeste Español, pp. 215-219.

VAN Ossel, P. (1992): Établissements ruraux de 1'Antiquité tardive dans le Nord de la Gaule. París.

- (1995): «L'Antiquité tardive (IVe-Ve siècles) dans I'llle-de-France, acquis et incertitudes», en LoRREN, C. y PÉRIN, P.: L'habitat rural du haut Moyen Age (France, Pays-Bas, Danemark et Grande-Bretagne). Actes des XIVe Journées internationales d'Archéologie mérovigienne, Guiry-en-Vexin et Paris, 4-8 février 1993, 63-79.

- (1997): «Structure, évolution et statut des habitats ruraux au Bas-Empire en lle-de-France», en Ouzoulias, P. y VAN Ossel, P. : Les campagnes de I'lle-de-France de Constantin à Clovis. Colloque de Paris, 14-15 mars 1996 / Rapports et synthèses de la deuxième journée, P.C.R. sur l'époque tardive en lle-de-France, Document de travail 3, Paris, pp. 94-118.

VAN OSSEL, P. y Ouzoulias, P. (2000): «Rural settlement economy in northern Gaul in the late empire: an overview», JRA, 13, pp. 133-160.

- (2001): «La mutation des campagnes de la Gaule du Nord entre le milieu du Ille siècle et le milieu du Ve siècle. Où en est-on?", en LODEWIJCKX, M.: Belgian archaeology in a European setting. Acta archaeologica Lovaniensia. Monographiae, 12-13, pp. 231-245.

VARGAS JimÉnEZ, J. M. y Romo SALAS, A. (1993): «Prospección arqueológica y diagnosis en la finca de Doña Ana (Dos Hermanas, Sevilla)». Anuario Arqueológico de Andalucía, 3, pp. 670-682.

VARGAS Jiménez, J. M., y Romo SalAs, A. (1997): «La villa romana de Doña Ana II (Dos Hermanas, Sevilla)", Anuario Arqueológico de Andalucía, 3, pp. 545-556.

Vigil-Escalera GuIRADO, A., (2000): «Cabañas de época visigoda: evidencias arqueológicas del Sur de Madrid. Tipología, elementos de datación y discusión», AEspA, 73, pp. 223-252. 